\title{
Mismatch Between the 1997/1998 Influenza Vaccine and the Major Epidemic A(H3N2) Virus Strain as the Cause of an Inadequate Vaccine-Induced Antibody Response to This Strain in the Elderly
}

\author{
Jan C. de Jong, ${ }^{1 *}$ Walter E.P. Beyer, ${ }^{1}$ Abraham M. Palache, ${ }^{2}$ Guus F. Rimmelzwaan, ${ }^{1}$ and \\ Albert D.M.E. Osterhaus ${ }^{1}$ \\ ${ }^{1}$ Department of Virology and WHO National Influenza Centre, Erasmus University, Rotterdam, The Netherlands \\ ${ }^{2}$ Solvay Pharmaceuticals, Weesp, The Netherlands
}

The success of influenza vaccination depends largely on the antigenic match between the influenza vaccine strains and the virus strains actually circulating during the season. In the past, this match has proved to be satisfactory in most seasons. In the 1997/1998 season, however, hemagglutination inhibition (HI) assays with ferret antisera indicated a considerable mismatch between the H3N2 vaccine component and the most prevalent epidemic influenza $A(H 3 N 2)$ virus. The results from antigenic analyses using pre- and postvaccination serum samples from volunteers of various ages, including residents of nursing homes who were more than 60 years of age, were in good agreement with the results obtained with ferret antisera. Homologous serum antibody responses to the H3N2 vaccine component as well as the cross-reactivity of the induced antibodies to the epidemic H3N2 strain, declined with increasing age of the vaccinees. As a consequence of these two effects, $84 \%$ of the vaccinees over 75 years of age did not develop $\mathrm{HI}$ antibody titers $\geq 40$ against the major H3N2 virus variant of 1997/1998, suggesting that they were not protected against infection with this virus variant. These findings support the current policy of the World Health Organization (WHO), which is to base worldwide influenza virus surveillance on results predominantly obtained by antigenic analyses of influenza virus isolates with ferret antisera in $\mathrm{HI}$ tests. If an antigenic mismatch is observed, the protective efficacy of the vaccine, especially for the elderly, may be insufficient. The observations also support the current policy to include the elderly in serologic efficacy trials. J. Med. Virol. 61:94-99, 2000. (c) 2000 Wiley-Liss, Inc.
KEY WORDS: influenza; vaccine; mismatch; efficacy; cross-reactivity

\section{INTRODUCTION}

The cornerstone for the prevention of influenza is annual vaccination with inactivated virus vaccines [Betts, 1995]. Because of the frequently occurring antigenic changes, the World Health Organization (WHO) coordinates a worldwide surveillance of influenza virus strains, characterized conventionally by their reactivity in hemagglutination inhibition (HI) assays with ferret antisera. Based on the results of these assays, the vaccine formulation is adapted yearly to include those virus variants that are most likely to circulate in the coming season. The effectiveness of this prophylaxis largely depends on the match between the vaccine strains and the circulating viruses [Mullooly et al., 1993]. This match has been fairly accurate over the past decades [Mullooly et al., 1993].

In the 1996/1997 season, viruses similar to A/Wuhan/359/95(H3N2) ("Wuhan") were responsible for moderately severe influenza epidemics in the Northern Hemisphere. As early as February 1996, the WHO foresaw the circulation of this variant and recommended the inclusion of a Wuhan-like virus component in the vaccine for the 1996/1997 season. This recommendation was repeated logically for the 1997/1998 season on the basis of data available in February 1997. In June 1997, however, a new variant of influenza virus subtype A(H3N2) - represented by prototype strain A/Sydney/5/97 ("Sydney")_emerged in Australia and New

\footnotetext{
*Correspondence to: J. C. de Jong, Department of Virology and WHO National Influenza Centre, Erasmus University, Dr Molewaterplein 50, 3015 GE Rotterdam, the Netherlands.

E-mail: jc.de.jong@wxs.nl

Accepted 22 September 1999
} 
Zealand, where it gave rise to extensive epidemics [Anonymous, 1998]. This same variant was the major cause of the epidemics in the Northern Hemisphere during the early months of 1998, together with sporadic circulation of Wuhan-like strains [Anonymous, 1998]. Although the epidemic was described as mild, the Netherlands Central Bureau of Statistics calculated an excess mortality of 1,400 for the Netherlands in the period from March to April 1998 [Prins, 1998]. This coincided with an influenza epidemic that lasted from mid-February until mid-April. In February 1998, the WHO recommended the inclusion of a Sydney-like strain in the influenza vaccine for the 1998/1999 season [Anonymous, 1998]. In the present study, the match between the Wuhan-like vaccine strain and the 1997/1998 Wuhan-like and Sydney-like field isolates was investigated by comparing the antibody responses induced in ferrets. Moreover, in order to assess the actual efficacy of the influenza vaccine used in the 1997/ 1998 season, the antibody responses of human influenza vaccinees to these viruses also were measured.

\section{MATERIALS AND METHODS Antigens}

The high-growth influenza A(H3N2) virus strain RESVIR-9 was used for the 1997/1998 vaccine which was administered to the participants of the present study. It was similar to the epidemic WHO reference strain A/Wuhan/359/95 and is therefore called "Wuhan vaccine" in this article. For the 1998/1999 vaccine, the high-growth influenza $\mathrm{A}(\mathrm{H} 3 \mathrm{~N} 2)$ virus strain IVR-108 was used. This strain was similar to the epidemic WHO reference strain A/Sydney/5/97 and is called "Sydney vaccine." Strains A/Netherlands/300/97 ("Sydney field") and A/Netherlands/005/98 ("Wuhan field") were chosen as representative of the Sydney-like and the Wuhan-like field strains, respectively, of the 1997/1998 epidemic.

\section{Serum Samples}

Three specific ferret antisera were prepared against the Wuhan vaccine and one each against the Sydney vaccine, Sydney field, and Wuhan field. The animals were bled 2 weeks after intranasal infection with the respective strains. The serum samples from vaccinees used in the present study were obtained in the course of three previous vaccination studies, each comprising 48 individuals. The first study group included healthy adults aged 19 to 57 years (median age, 28 years), the second group were free-dwelling elderly individuals aged 60 to 77 years (median age, 65 years), and the third group was made up of elderly persons living in nursing homes who were aged 61 to 99 years (median age, 82 years). All 144 individuals had been vaccinated with one dose of a standard commercial trivalent influenza subunit vaccine manufactured by Solvay Pharmaceuticals (Weesp, The Netherlands), containing $15 \mu \mathrm{g}$
TABLE I. Antigens Used in the HI Titrations

\begin{tabular}{llc}
\hline Influence virus strain & Name & $\begin{array}{c}\text { Medium in } \\
\text { which isolated } \\
\text { and grown }\end{array}$ \\
\hline $\begin{array}{l}\text { RESVIR-9, } \\
\text { A/Wuhan/359/95-like } \\
\text { reassortant, 1997/1998 }\end{array}$ & Wuhan vaccine & $\begin{array}{c}\text { Embryonated } \\
\text { fowl eggs }\end{array}$ \\
vaccine & & \\
A/Netherlands/005/98, & Wuhan field & $\begin{array}{c}\text { MDCK cell } \\
\text { A/Wuhan/359/95-like }\end{array}$ \\
$\begin{array}{l}\text { A/Netherlands/300/97, } \\
\text { A/Sydney/5/97-like }\end{array}$ & Sydney field & $\begin{array}{c}\text { MDCK cell } \\
\text { culture }\end{array}$ \\
$\begin{array}{l}\text { IVR-108, } \\
\text { A/Sydney/5/97-like } \\
\text { reassortant, 1998/1999 }\end{array}$ & Sydney vaccine & $\begin{array}{c}\text { Embryonated } \\
\text { fowl eggs }\end{array}$ \\
vaccine & & \\
\hline
\end{tabular}

HI, hemagglutination inhibition; MDCK, Madin Darby Canine Kidney.

hemagglutinin of each component. The vaccine contained RESVIR-9 as the H3N2 component.

The first and second study groups were vaccinated with batch L-0202 in July 1997 and the third group with batch K-0302 in December 1996. In the first study group, four participants also had been vaccinated in 1982, 1987, 1991, and 1991, respectively. None of the participants had suffered an influenza-like illness in the year before vaccination. Among the second study group, two participants had been vaccinated in 1987 and 1991, respectively. Two other subjects of this group had experienced an influenza-like illness in the year before vaccination, in January 1996 and May 1997, respectively. No data for histories of vaccination or influenza-like illness were available for the participants of the third study group. A blood sample was taken from each vaccinee just before vaccination and 15 (study groups 1 and 2) or 21-23 days (group 3) later.

In a linear regression model using the postvaccination titer as a dependent variable and prevaccination titers, age, and study group as independent variables, prevaccination titers and age, but not the study group, proved to influence significantly the postvaccination titers. Therefore, in the present article the data are provided for three age classes $(19-59,60-74$, and 75-99 years of age) rather than for the three study groups. The absence of an effect of the study group in the linear regression analysis also shows that the differences between the various study groups in the time of vaccination and in the batch of vaccine used did not influence significantly the results of the study.

\section{Hemagglutination Inhibition Assays and Statistical Analysis}

HI assays were carried out essentially as described by Masurel et al. [1981]. All sera were titrated twice against the four antigens listed in Table I. HI titers were expressed as the reciprocals of the highest serum dilution that completely inhibited hemagglutination by four hemagglutination units of the test antigen. If no HI was observed (titer lower than 20), the titer was 
TABLE II. Cross-reactivities of the Antigens Used in HI Assays With Ferret Antisera

\begin{tabular}{|c|c|c|c|c|c|c|}
\hline \multirow{2}{*}{$\begin{array}{l}\text { Influenza } \\
\text { virus strain }\end{array}$} & \multicolumn{6}{|c|}{ Postinfection HI titers of ferret antisera against ${ }^{\mathrm{a}}$} \\
\hline & \multicolumn{3}{|c|}{ Wuhan vaccine (three antisera) } & \multirow{2}{*}{$\frac{\text { Wuhan field }}{1,280}$} & \multirow{2}{*}{$\frac{\text { Sydney field }}{40}$} & \multirow{2}{*}{$\frac{\text { Sydney vaccine }}{80}$} \\
\hline Wuhan vaccine & 640 & 1,280 & 1,280 & & & \\
\hline Wuhan field & $\overline{320}$ & $\frac{320}{320}$ & $\frac{320}{320}$ & 1,280 & 80 & 80 \\
\hline Sydney field & 80 & 160 & 40 & 320 & 2,560 & 5,120 \\
\hline Sydney vaccine & 80 & 80 & $<20$ & 80 & $\overline{2,560}$ & 5,120 \\
\hline
\end{tabular}

HI, hemagglutination inhibition.

${ }^{a}$ Homologous titers are underlined and set in bold type.

TABLE III. Postvaccination Geometric Mean Titers Against the Wuhan Vaccine and Sydney Field and Their Quotient*

\begin{tabular}{lcccc}
\hline & & \multicolumn{3}{c}{ Antigens used in the HI titrations } \\
\cline { 3 - 5 } Age class & $\mathrm{N}$ & Wuhan vaccine & Sydney field & Wv/Sf \\
\hline $19-59 \mathrm{yr}$ & 48 & $794(592-1,066)$ & $111(78-156)$ & $7.2(5.9-8.8)$ \\
$60-74 \mathrm{yr}$ & 56 & $255(186-351)$ & $42(29-61)$ & $6.1(4.6-8.1)$ \\
$75-99 \mathrm{yr}$ & 40 & $196(137-426)$ & $18(13-42)$ & $11.2(8.5-14.8)$ \\
$P$ (one-way & & $\leq 0.001$ & $\leq 0.001$ & 0.005 \\
ANOVA) & & &
\end{tabular}

HI, hemagglutination inhibition; Wv/Sf, post-vaccination geometric mean titer (post-GMT) against Wuhan vaccine/post-GMT against Sydney field.

*The $95 \%$ confidence intervals are given in parentheses.

arbitrarily recorded as 10 for calculation. The logarithms of the pre- and postvaccination titers were confirmed to be normally distributed by the Kolmogorov Smirnov KS Goodness of Fit Test for Normal Distribution (SPSS for Windows 5.0). Comparisons between different viruses within a given age class were made using the paired $t$ test (titers) and the McNemar $\chi^{2}$ test (proportions). Comparisons between age classes were made using one-way ANOVA (titers) and the Pearson $\chi^{2}$ test (proportion). Differences between test results were regarded as significant when $P$ was $<0.05$. Confidence intervals were calculated using the Confidence Interval Analysis software (version 1.0, 1989; S. B. Gardner, P. D. Winter, and M. J. Gardner, distributed by the British Medical Journal, London). The " $50 \%$ protective threshold" of $\mathrm{HI}$ antibodies was set at 40 ( $\geq 40$ being considered protective), in accordance with usual practice [Arden et al., 1986].

\section{RESULTS Ferret Antisera}

The three ferret antisera raised against the Wuhan vaccine showed HI titers against the Wuhan field that were only two- to fourfold lower than the HI titers against the Wuhan vaccine (Table II). However, HI titers of these antisera measured against the Sydneylike field strains, which were the major cause of the 1997/1998 epidemic [Anonymous, 1998] and which were represented by the Sydney field in the present study, were eight- to 32-fold lower than those measured against the Wuhan vaccine. The HI data obtained with ferret antisera raised against the two Sydney-like viruses confirmed the major antigenic difference between the Wuhan- and Sydney-like strains.

\section{Serum Samples From Vaccinees}

The homologous serum HI antibody responses to the Wuhan vaccine and the response to the Wuhan field varied from strong in young people to fair in middleaged persons to moderate in the older age class (Table III and Fig. 1). The responses to the Sydney field were 7.2-, 6.2-, and 11.2-fold, respectively, lower than the responses to the Wuhan vaccine. In each of the three cases, the differences between the titers to the two viruses are statistically significant. Moreover, the differences among the three mentioned quotients are statistically significant (Table III). For the three age classes, the percentages of vaccinees showing a "protective" HI titer of $\geq 40$ after vaccination were $100 \%, 93 \%$, and $93 \%$, respectively, against the Wuhan vaccine and $88 \%$, $48 \%$, and $22 \%$, respectively, against Sydney field (Fig. 2 ). A better evaluation of the performance of the vaccines is obtained when the results of vaccination are calculated only for those vaccinees who had prevaccination titers of $<40$. In the present study, the data obtained in this way are roughly similar to the data for all vaccinees (Table IV). The greatest difference was in the oldest age class: only $16 \%$ of the subjects with prevaccination $\mathrm{HI}$ titers of $<40$ acquired a protective antibody level.

\section{DISCUSSION}

In the 1997/1998 season, there was a mismatch between the H3N2 influenza vaccine component (Wuhan vaccine) and the major epidemic H3N2 strain (Sydney field). In the present study, sera were used from ferrets after infection with various influenza virus strains and from humans under 60 years of age, free-dwelling el- 

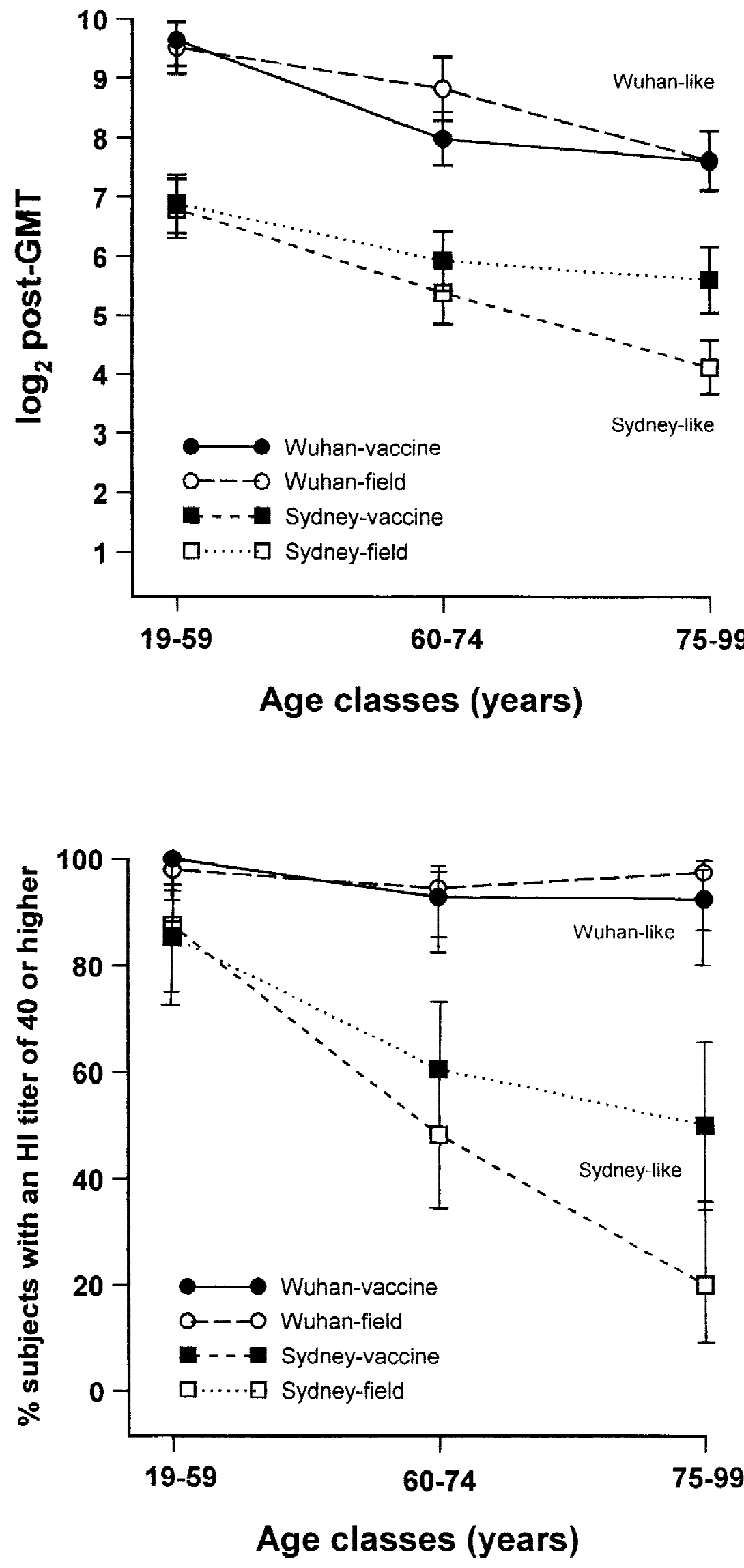

Fig. 1. Postvaccination geometric mean titer on a $\log _{2}$ scale of serum samples from individuals vaccinated with Wuhan vaccine, according to three age classes. The vertical bars indicate the $95 \%$ confidence intervals.
Fig. 2. Proportions of subjects with postvaccination titers of 40 or higher, according to three age classes. The vertical bars indicate the $95 \%$ confidence intervals. 
TABLE IV. Numbers and Percentages of Vaccinees Who Had a Prevaccination HI Titer of $<40$ and Acquired a Postvaccination HI Titer of $\geq 40$

\begin{tabular}{lcccc}
\hline & \multicolumn{3}{c}{ Antigens used in the HI titrations } \\
\cline { 2 - 5 } Age class & Wuhan vaccine & Wuhan field & Sydney field & Sydney vaccine $^{\mathrm{a}}$ \\
\hline $19-59 \mathrm{yr}$ & $25 / 25(100 \%)$ & $26 / 27(96 \%)$ & $40 / 46(87 \%)$ & $36 / 43(84 \%)$ \\
$60-74 \mathrm{yr}$ & $37 / 41(90 \%)$ & $29 / 32(91 \%)$ & $26 / 55(47 \%)$ & $32 / 53(60 \%)$ \\
$75-99$ yr & $18 / 21(86 \%)$ & $14 / 15(93 \%)$ & $6 / 37(16 \%)$ & $16 / 36(44 \%)$ \\
$P\left(\chi^{2}\right.$ test $)$ & $>0.05$ & $>0.05$ & $<0.001$ & 0.001 \\
\hline
\end{tabular}

HI, hemagglutination inhibition.

aThe differences between the percentages for the three classes of vaccinees are statistically significant for the two Sydney-like antigens (Pearson $\chi^{2}$ test).

derly, and residents of nursing homes before and after vaccination with the influenza vaccine for the 1997/ 1998 season. The mean difference between the HI titers to the Wuhan vaccine and the Sydney field proved to be eight- to 32 -fold using ferret antisera (Table II) and about six- to 11-fold using sera from human vaccinees (Table III). These observations are in line with preliminary results published by the WHO for adults and elderly vaccinated with the Wuhan vaccine [Anonymous, 1998]. The results show that homologous and heterologous postvaccination geometric mean titer (post-GMT), as well as the percentage of subjects with postvaccination titers $\geq 40$, declined with increasing age (Figs. 1 and 2).

In particular, the mismatch affected the immune response to influenza vaccination in the 75- to 99-yearold participants. In these subjects, the vaccine-induced antibodies not only had a low titer to Wuhan vaccine but also proved to be significantly less cross-reactive to the Sydney field than the vaccine-induced antibodies in the two younger age classes (11-fold versus six- to seven-fold differences in post-GMT to the Wuhan vaccine and the Sydney field, respectively; Table III). In the study group of nursing home residents, vaccineinduced antibodies were significantly less crossreactive than those in the adults under 60 years of age and the free-dwelling elderly participants over the age of 60 years (10-fold versus seven- and sixfold differences in post-GMT to the Wuhan vaccine and the Sydney field, respectively; $P=0.014$ ). A comparison of the results from nursing home residents with those from free-dwelling elderly in the same age range (61-77 years of age), however, did not elicit a statistically significant difference in the immune response (data not shown). Apparently, the lower cross-reactivity found in the nursing home residents can be ascribed to the effect of increasing age. This observed age effect is in line with the findings of previous studies that suggest that senescence, in particular, leads to an impaired ability to respond to newly emerging influenza virus epitopes (in this study the epitopes present in the Wuhan- and Sydney-like strains but not in earlier vaccine or epidemic strains), a phenomenon that may be related to the "original antigenic sin" [Beyer et al., 1989; McElhaney et al., 1993; Powers and Belshe, 1994].

The proportions of vaccinees who acquired at least the presumed $50 \%$ protective antibody titer of 40 against Sydney field were $87 \%, 47 \%$, and $16 \%$, respectively, for the three age classes (Table IV). For the elderly, especially for older residents of nursing homes, who form a major target for protection against complications and death by influenza [Betts, 1995], this observation implies insufficient induction of immunity to the Sydney-like viruses. The data show that the results from antigenic analyses with ferret antisera were in good agreement with those obtained using sera from vaccinees. The results support the effectiveness of the WHO worldwide surveillance system, which, for practical reasons, is largely based on the use of animal antisera. Furthermore, they confirm that vaccination trials in adults less than 60 years of age should be considered at face value, bearing in mind that the antibody response may be less pronounced in the elderly. The success of the WHO worldwide influenza surveillance program is illustrated by the rare occurrence of antigenic mismatches, such as that described in the present study. When ongoing surveillance data indicate such a mismatch, the WHO should consider a change from its original recommendation (despite the serious practical implications) and recommend the production of a vaccine based on the newly emerged epidemic strain. This policy was adopted in 1986, when the A/Taiwan/86 (H1N1) strain appeared in August of that year [Anonymous, 1986].

\section{ACKNOWLEDGMENTS}

The authors thank R. van Beek, M. Baars, and L. J. van der Kemp for their excellent technical assistance.

\section{REFERENCES}

Anonymous. 1986. Recommended composition of influenza vaccines for use in the 1986/87 season: an update. Wkly Epidemiol Rec 61:237-244.

Anonymous. 1998. Recommended composition of influenza virus vaccines for use in the 1998-1999 season. Wkly Epidemiol Rec 73:5661.

Arden NH, Patriarca PA, Lui KJ, Harmon MW, Brandon F, Kendal AP. 1986. Safety and immunogenicity of a $45 \mu \mathrm{g}$ supplemental dose of inactivated split-virus influenza B vaccine in the elderly. J Infect Dis 153:805-806.

Betts RF. 1995. Influenza virus. In: Mandell GL, Bennett JE, Dolin R, editors. Principles and Practice of Infectious Diseases. New York: Churchill Livingstone. p 1546-1567.

Beyer WEP, Palache AM, Baljet M, Masurel N. 1989. Antibody induction by influenza vaccines in the elderly: a review of the literature. Vaccine 7:385-394.

Masurel N, Ophof P, de Jong P. 1981. Antibody response to immuni- 
zation with influenza A/USSR/77 (H1N1) virus in young individuals primed or unprimed for A/New Jersey/76 (H1N1) virus. J Hyg (Camb) 87:201-209.

McElhaney JE, Meneilly GS, Lechelt KE, Beattie BL, Bleackley RC. 1993. Antibody response to whole-virus and split-virus influenza vaccines in successful ageing. Vaccine 11:1055-1060.

Mullooly J, Bennett M, Hornbrook M, Williams W, Patriarca P, Rhodes P. 1993. Cost-effectiveness of influenza vaccination programs in an HMO: the experience of Kaiser Permanente, Northwest Region. In: Hannoun C, Kendal AP, Klenk HD, Ruben FL, editors. Options for the Control of Influenza II. Proceedings of the International Conference on Options for the Control of Influenza, Courchevel, 27 September to 2 October 1992. Amsterdam: Elsevier Science Publishers. p 53-62.

Powers DC, Belshe RB. 1994. Vaccine-induced antibodies to heterologous influenza A H1N1 viruses: effects of aging and "original antigenic sin.” J Infect Dis 169:1125-1129.

Prins CJM. 1998. Many deaths in March and April 1998. Monthly Bulletin of Population Statistics (Maandstatistiek van de Bevolking, CBS) 46:8-9. [Dutch article with English summary]. 